\title{
Older Adults' Perceptions of Supporting Factors of Trust in a Robot Care Provider
}

\author{
Rachel E. Stuck $\mathbb{D}^{1}$ and Wendy A. Rogers ${ }^{2}$ \\ ${ }^{1}$ Georgia Institute of Technology, 654 Cherry St., Atlanta, GA 30332, USA \\ ${ }^{2}$ University of Illinois Urbana-Champaign, 1206 South 4th St, Champaign, IL 61820, USA \\ Correspondence should be addressed to Rachel E. Stuck; stuck.rachel@gatech.edu
}

Received 10 November 2017; Revised 2 February 2018; Accepted 15 February 2018; Published 1 April 2018

Academic Editor: Yunyi Jia

Copyright (C) 2018 Rachel E. Stuck and Wendy A. Rogers. This is an open access article distributed under the Creative Commons Attribution License, which permits unrestricted use, distribution, and reproduction in any medium, provided the original work is properly cited.

\begin{abstract}
The older adult population is increasing worldwide, leading to an increased need for care providers. An insufficient number of professional caregivers will lead to a demand for robot care providers to mitigate this need. Trust is an essential element for older adults and robot care providers to work effectively. Trust is context dependent. Therefore, we need to understand what older adults would need to trust robot care providers, in this specific home-care context. This mixed methods study explored what older adults, who currently receive assistance from caregivers, perceive as supporting trust in robot care providers within four common homecare tasks: bathing, transferring, medication assistance, and household tasks. Older adults reported three main dimensions that support trust: professional skills, personal traits, and communication. Each of these had subthemes including those identified in prior human-robot trust literature such as ability, reliability, and safety. In addition, new dimensions perceived to impact trust emerged such as the robot's benevolence, the material of the robot, and the companionability of the robot. The results from this study demonstrate that the older adult-robot care provider context has unique dimensions related to trust that should be considered when designing robots for home-care tasks.
\end{abstract}

\section{Introduction}

The population of older adults is increasing worldwide at an advanced rate. A recent World Health Organization (WHO) report on aging emphasized the need to have tailored interventions for these aging populations, such as older adults with care providers [1]. As the number of older adults increases so will the demand for care providers and, with an insufficient number of humans to fill the demand, robots might help fulfill this need. Trust is essential for older adults to successfully interact with robot care providers, and we need an in-depth understanding about the factors that influence trust within this specific context of an older adult and robot care provider.

To gain an understanding of what factors might emerge, we first reviewed human-human trust research but found that it had not been specifically explored in the context of care providers. However, in general, key elements in human-human trust are the characteristics of the trustee, characteristics of the trustor [2], and the relationship [3]. For the perceived characteristics of the trustor, the ability, values, and benevolence all contributed to trust [2]. In the patientnurse trust literature, there were several elements apart from ability, reliability, and other task specific characteristics that contributed to trust. Patients wanted to feel respected [4] and cared for, especially in situations where they felt vulnerable [5]. In addition, as trust developed, the communication between the nurse and patient became a key element in what influenced how the patient perceived the trustworthiness of the nurse [4]. These findings give insight into trust, but it is unclear if these factors will also emerge in the human-robot context.

Human-automation trust provided the basis for humanrobot trust. Trust of automation is associated with use of that automation [6]. For example, if an operator trusts a system then they are more likely to use the system. This highlights the key need to understand and support trust for appropriate use of a system. Aspects that influence trust in automation include characteristics of the automation such as 
the quality of the system feedback [7] and the reliability of the system [8]. For example, lack of reliability and failures of the system negatively impact trust [6]. However, the relationship between failures and trust is complicated and does not have a one-to-one ratio in lowering trust [6]. Characteristics of the operator also influence trust such as the operator's selfconfidence [9] and their personality traits [10].

With the increase of robots in workplace and the home, research has also focused on trust specifically in robots. A model of trust was developed by Sanders et al. [11] that identified the main components that contribute to humanrobot team trust. These included the characteristics of the person, the characteristics of the robot, the environmental characteristics, and the training and design implications. The person's characteristics included aspects such as personality, self-confidence, general attitude towards robots, and knowledge of the robot [11, 12]. The qualities of the robot included elements related to the robot's performance such as the reliability and predictability [11-13]. Other qualities included the proximity of the robot to the human, type of robot, and the appearance of the robot $[12,13]$. The environmental characteristics included the type of task and communication [11]. Training and design implications demonstrate how these are influenced by both the human and the robot qualities and thereby influencing trust [11, 14]. A framework that identified key components of human-robot interaction with older adults also identified many of these components including the human characteristics (e.g., psychographics, abilities), robot characteristics (e.g., appearance, capabilities), tasks constraints (e.g., proximity, accuracy requirements), and context of the interaction (e.g., living environment, safety considerations) [15].

Research has also explored older adults' attitudes towards robots in the home. Smarr et al. [16] explored healthy, independent living older adults' acceptance of robots in the home as well as what tasks they preferred a robot to do. Older adults in this study were generally accepting of a robot, but they had preferences about the type of tasks they preferred a robot to perform [16]. The older adults preferred a robot over a human for tasks related to household chores, manipulating objects, or information management [16]. In another study, older adults' acceptance of robots in the home was confirmed as they reported that they would prefer to stay at home with a robot than have to go to a facility [13]. After exposure to an assistive robot, older adults not only reported higher perceptions of usefulness but also a greater willingness to have the robot assist with various tasks [17].

One study specifically focused on trust between older adults and home robots [18]. Reliability, precision, efficiency, and safety were the top descriptors used for a trustworthy robot [18]. However, this study was limited as it did not specifically assess the role of the task, a key component of trust, and also interviewed older adults who did not necessarily have any experience with receiving care.

A first step in exploring trust in the home-care context is to understand older adults' perceptions of robot care providers and what traits the older adults want the robot care provider to have to trust it. Perceptions influence technology acceptance such as the perceived benefits or concerns of using the technology [19]. In the human-human trust literature, the trustor's perceptions of the trustee influenced the decision to trust $[2,20]$. In addition, studies have shown that an individual's perception of a robot influenced how they interacted with it [21]. Insight into what factors older adults perceive as necessary for them to trust a robot will allow us to support their development of trust and diminish acceptance issues that are related to perceptions of the robot being untrustworthy.

The focus of this paper is to explore what factors older adults who currently receive care identify as supporting trust in a robot care provider. In particular, the goal was to address these specific research questions:

(1) Do the dimensions of trust identified in the literature emerge in the older adult-robot care provider relationship?

(2) Do new dimensions of trust emerge in the older adultrobot care provider relationship?

This research is part of a larger project that explored trust in human care providers as well. For details about the rest of the project see [22].

\section{Method}

2.1. Participants. We interviewed 24 older adults (12 in independent living and 12 in assisted living) above the age of $65(\mathrm{M}=81, \mathrm{SD}=7.13$, age range 67-96) who received 4 or more days of care a week. On average, they received around 6 days of care with the caregiver staying around 1-3 hours each visit. Participants were recruited through outreach to local independent and assisted living communities. They were primarily females. They were diverse in ethnicity and education. Overall, participants reported that they had fair health. On average, the participants cognitive function was at a scoring on the Montreal Cognitive Assessment (MOCA) that represents mild cognitive impairment [26]; note that 5 participants were unable to complete cognitive assessment due to vision or physical impairment. Participants were on average moderately confident performing daily living tasks, but there was a lot of variability between participants and tasks. When asked about technology experience, the participants reported no usage to relatively low usage. For a detailed list of descriptors see Table 1.

2.2. Procedure. Prior to inclusion in the study, participants were screened in person or via telephone to ensure that they met the eligibility criteria which included passing the Wechsler Memory Scale III [27] to ensure that they would be able to follow along with the interview. All participants gave informed consent prior to participation in the study. Participants were then given several questionnaires before the interview (Table 2).

Following the questionnaires, a semistructured interview was administered to investigate the participants' perceptions of what factors support trust. The order of the interview questions was counterbalanced between discussions of the robot care provider and the human care provider to control 
TABLE 1: Participant characteristics.

\begin{tabular}{|c|c|c|}
\hline Factor & Measure & $\begin{array}{c}\% \text { of } \\
\text { participants }(n)\end{array}$ \\
\hline Ethnicity & $\begin{array}{c}\text { Black/African American } \\
\text { White/Caucasian } \\
\text { Others }\end{array}$ & $\begin{array}{c}29 \%(7) \\
67 \%(16) \\
4 \%(1)\end{array}$ \\
\hline Education & $\begin{array}{c}\text { Less than high school graduate } \\
\text { High school graduate/GED } \\
\text { Some or in-progress college/associates degree } \\
\text { Bachelor's degree (BA, BS) } \\
\text { Master's degree } \\
\text { Doctoral degree }\end{array}$ & $\begin{array}{c}8 \%(2) \\
17 \%(4) \\
71 \%(10) \\
13 \%(3) \\
13 \%(3) \\
8 \%(2)\end{array}$ \\
\hline General health $^{\mathrm{a}}$ & "In general, would you say your health is..." & $\begin{array}{l}M=2.38 \\
S D=1.06\end{array}$ \\
\hline $\begin{array}{l}\text { Montreal cognitive } \\
\text { assessment }^{\mathrm{b}}(n=19)\end{array}$ & & $\begin{array}{l}M=23.05 \\
S D=4.01\end{array}$ \\
\hline $\begin{array}{l}\text { Days assistance received each week } \\
(n=23)^{*}\end{array}$ & & $\begin{array}{l}M=6.05 \\
S D=1.53\end{array}$ \\
\hline Average length of caregiver stay ${ }^{c}$ & & $\begin{array}{l}M=2.00 \\
S D=1.05\end{array}$ \\
\hline Technology usage $^{\mathrm{d}}$ & "In the past year, how often have you used..." & $\begin{array}{l}M=0.79 \\
S D=0.57\end{array}$ \\
\hline Self-efficacy for daily tasks ${ }^{\mathrm{e} *}$ & "How confident are you in performing. ..?" & $\begin{array}{l}M=61.26 \\
S D=29.13\end{array}$ \\
\hline
\end{tabular}

(a) 1 = poor, 2 = fair, 3 = good, $4=$ very good, $5=$ excellent; (b) score $\geq 26$ = normal; (c) $1=$ less than an hour, $2=1-3$ hours, $3=4-6$ hours, $4=6-12$ hours, and $5=12-24$ hours; (d) $0-$ not used; $1=$ used once, $2=$ used occasionally, and $3=$ used frequently; (e) $1=$ not at all confident and $10=$ completely confident (summed across 10 questions; range is $10-100) ;{ }^{*}$ one participant did not wish to answer.

TABLE 2: Preinterview questionnaires.

\begin{tabular}{llc}
\hline Questionnaire title & Description of measured variables & Reference \\
\hline (1) Demographic/health & $\begin{array}{l}\text { General descriptive information about the health and } \\
\text { hearing/vision/motor capabilities of the participants }\end{array}$ & Czaja et al. [23] \\
(2) Technology experience profile & $\begin{array}{l}\text { Usage and experience with various types of technologies within the last } \\
\text { year }\end{array}$ & Barg-Walkow et al. [24] \\
(3) Daily living self-efficacy scale & Level of confidence on various ADL and IADL tasks & Sanford et al. [25] \\
(4) Assistance level with daily tasks & $\begin{array}{l}\text { Level of assistance with various ADL and IADL tasks, who assists them, } \\
\text { and how often they receive help }\end{array}$ & Locally developed \\
(5) Formal caregiver experience & $\begin{array}{l}\text { Information about experience with caregiver either personal or through } \\
\text { assisted living }\end{array}$ & Locally developed \\
(6) Montreal cognitive assessment & General cognitive ability and level of cognitive impairment & Nasreddine et al. [26] \\
\hline
\end{tabular}

for carry over effects (the focus of the present paper is on the discussion of the robot care provider only). To gain a deeper insight and provide context, we explored what supported trust within 4 task scenarios: bathing, medication assistance, transfer, and household tasks (see Table 3). The scenarios were developed with the help of three subject matter experts (SMEs). We chose two activities of daily living (ADLs; bathing and transferring) and two instrumental activities of daily living (IADLs). These tasks were chosen because they are some of the most frequent tasks of formal care providers for older adults in their homes [28] and bathing was added upon recommendation by the SMEs.

Bathing was discussed first as it contains the greatest amount of vulnerability. Participants were asked in general what a robot care provider would need to be like for them to trust it with that task and what would cause them to not trust the robot. Bathing was discussed in-depth with specific questions about previously identified dimensions specifically from human-human (values and benevolence), human-robot literature (precision and predictability), and dimensions discussed in both (ability, reliability, appearance, and communication). For each of the following tasks, we asked general questions about how they would want a robot care provider to be to trust it to perform the task and what would negatively impact their trust.

After completing the interview, the participants completed several follow-up questionnaires (Table 4). They were then compensated $\$ 30.00$ for their time and effort and debriefed about the purpose of the study. The interviews were audio recorded and then transcribed. 
TABLE 3: Scenario descriptions for each task.

\begin{tabular}{ll}
\hline Imagine you have a new formal caregiver who is going to assist you with \\
\hline Bathing & This will include them helping you remove your clothes and physically helping you \\
bathe & This means they would help remind you to take medications at the appropriate time \\
Medication & and perhaps bring the medication bottle to you \\
assistance & This will include the caregiver helping you sit up, lifting you, and moving you to the \\
Transferring & wheelchair \\
Household tasks & These tasks will include helping plan and prepare meals and doing some light \\
& housework such as laundry, doing the dishes, or making the bed
\end{tabular}

TABLE 4: Postinterview questionnaires.

\begin{tabular}{lcc}
\hline Questionnaire title & Description of measured variables & Reference \\
\hline (1) Robot self-efficacy scale & Level of confidence operating a robot & Locally developed \\
(2) Robot familiarity and usage & Assessed familiarity and usage of various robots & Smarr et al. [16] \\
(3) Trust preference checklist & Preference of human versus robot care provider for various tasks & Olson [18] \\
\hline
\end{tabular}

\section{Results and Discussion}

3.1. Overview of Analysis. We asked participants about what they perceived as supporting trust in a robot care provider across four tasks. The goal was to understand in general what factors support trust in a robot care provider, so the data presented are collapsed across tasks. However, when there were differences across tasks, we highlight those differences.

One individual coder segmented all the interviews into units of analysis. A segment was defined as a section of responses that related to one specific task. The coding scheme was developed based on prior research on trust as well as themes that emerged from the interviews $[29,30]$. The coding scheme categorizes the qualitative data to understand similar attitudes amongst participants. To identify emerging themes, four interviews were randomly selected and reviewed by two coders to discuss themes that emerged that did not fit into previously identified themes.

After development of the coding scheme, three independent rounds of intercoder agreement were conducted. For each round, using MAXQDA Version 12, Cohen's Kappa was calculated to ensure that coders were in agreement at a minimum threshold of $85 \%$ based on prior research that recommends between 80 and $90 \%$ as a minimum level of agreement [31]. For each round, if agreement was not met, coders met to discuss discrepancies and used this to inform the design of the coding scheme. For the final round, a reliability of $91.61 \%$ was met. Interviews were then divided between coders and independently coded.

To distinguish the most frequent factors for each overall theme, we used a threshold of $5 \%$ as a cutoff. There is no standardization for a cutoff, but previous qualitative research has used $5 \%$ as a method of reducing attention on categories that were not prominent across participants [32]. Excel was used to calculate frequencies and descriptive statistics for the questionnaires and response frequencies.

3.2. Robot Experiences and Attitudes. In general, participants had limited to no experience with robots $(\mathrm{M}=1.25, \mathrm{SD}=0.59)$

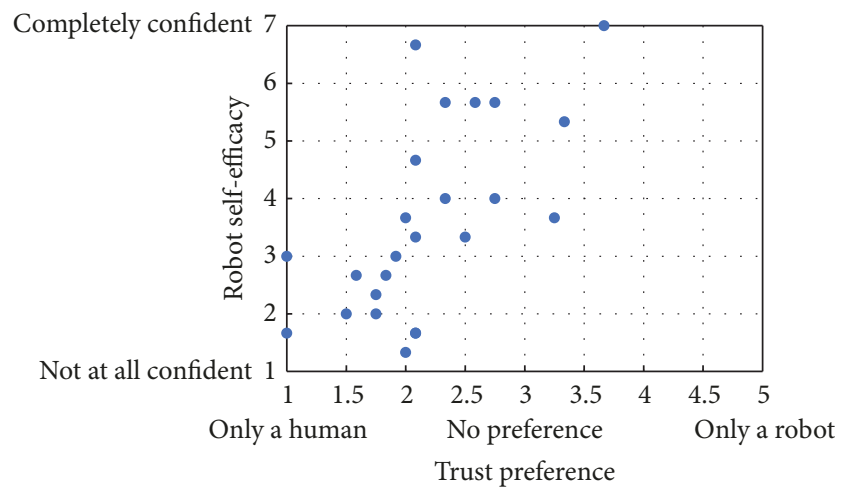

FIGURE 1: Relation of self-efficacy to trust preference.

based on a familiarity rating of 0 : not sure what this is, 1 : never heard about, seen, or used this robot, 2: have only heard about or seen this robot, 3: have used or operated this robot only occasionally, 4: have used or operated this robot frequently. Only 5 participants had ever used or operated a robot only occasionally (1: domestic robots, 3: entertainment robots, and 1: research robot).

We also assessed participants' self-efficacy (their belief in their ability to succeed) of being able to operate a robot in three situations (if there was no one around to tell them what to do, if they only had the robot manuals for reference, and if someone else showed them how to use it first). They rated on a scale of $1-7$ how confident they were $(1=$ not at all confident, 7 = completely confident). In general participants had low to neutral self-efficacy in operating the robot $(\mathrm{M}=3.61$; $\mathrm{SD}=$ 1.67).

When asked if they would prefer to trust a robot or a human for a list of various home-care tasks, participants overall reported that they preferred to trust a human $(\mathrm{M}=$ 2.18; $\mathrm{SD}=0.66 ; 1$ : only a human, 2 : prefer a human, 3 : no preference, 4: prefer a robot, and 5: only a robot).

Figure 1 illustrates the relationship between self-efficacy of operating a robot and trust preference. There was a positive 


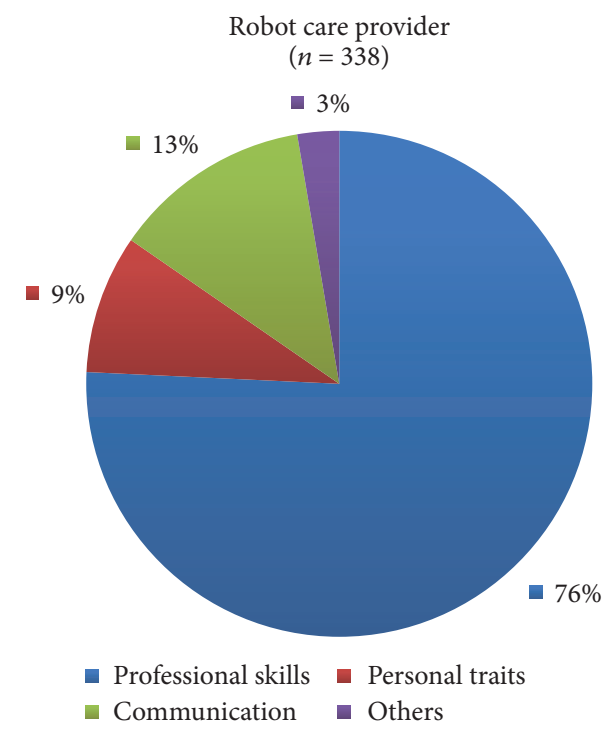

FIGURE 2: Trust factors across all tasks.

correlation $(r=.65, p<0.01)$ between self-efficacy and trust preference. Although this needs further exploration, perceived self-efficacy in operating a robot may make older adult users more open to trusting a robot to assist them. If this is the case, when providing robots for use by older adults, it would be important to design the robots so that they are easy to use and to train the older adults so that they feel confident in getting the robot to perform a task.

3.3. Trust Factors for Robot Care Providers. In the interviews, three main themes emerged as supporting trust in a robot care provider: professional skills, personal traits, and communication (see Figure 2). Overall, professional skills were the most frequently discussed factors that older adults perceived as supporting trust in a robot care provider. This factor was followed by communication and then personal traits. Personal traits may not have been discussed as frequently because of the participants' limited experience with robots.

Within each of these themes there were several factors from prior literature that emerged within this specific context. We will examine the details of these in the sections below.

3.3.1. Professional Skills. Within professional skills, the most frequently mentioned themes were general capability, precision, consistency of performance, safety, predictability, and gentleness (see Figure 3). A theme not previously identified in literature that emerged within this context was gentleness. Table 5 provides information on how we defined these themes, and an example quote from the interviews for the most frequently discussed themes in this category.

Within the tasks, there was some variability in the prevalence of each of these factors. For the task of bathing, $20 \%$ of participants reported wanting the robot care provider to have had prior experience with bathing, but this was not mentioned for other tasks. There were a few specific factors that seemed to be prevalent in tasks that involved touch (bathing and transfer). For example, safety and gentleness were mentioned most frequently for these two tasks. Contextual knowledge, which is defined as understanding the capabilities and sensitivities of the older adult, was also only mentioned for these two tasks. Thus, for tasks in which there is human-robot touch, there are other considerations to take into account. Particularly, older adults receiving care are commonly suffering from a chronic condition that may cause specific sensitivities that need special consideration in tasks where the robot is in contact with their body. One element that was unique for transferring was that older adults wanted to know that the robot was physically capable of lifting them, but physical capability was not mentioned as frequently for other tasks.

For medication assistance, 37.5\% mentioned that the robot needed to be on time, whereas this was only mentioned once for bathing and once for household tasks. This provides another example of how, for specific tasks, there are key elements of the tasks that are more salient to the older adults than for other tasks. A key aspect of medication management is ensuring that medications are administered at the required time and this importance increases with the more medications that are being managed leading to the older adults want to be sure that the medication would be given at the appropriate time.

Previously identified themes such as general capability and reliability were also pertinent to the context of a robot care provider. Beyond these themes, there were factors that influenced the participants' perceptions related to trust such as the gentleness with which the task is performed or how safely it is performed. Some of these factors were more salient within specific tasks. When designing for specific tasks, first identify what the key components are for the user within this task and then designers should try to ensure that those expectations are met. For example, for tasks involving human-robot touch a primary goal might be that the robot is gentle and safe, but with medication assistance, the focus of design should be on ensuring the robot can deliver the medication at the appropriate time.

3.3.2. Personal Traits. For personal traits, the main factors that emerged were the material or texture of the robot, the general appearance of the robot, the compatibility of the robot, the congruence of the care provider values with the older adult's values, the benevolence and kindness of the robot, and how the robot was dressed. See Figure 4 for the frequency of factors mentioned in professional skills. See Table 6 for the list of definitions and example quotes for each of these themes.

We also asked the participants after discussing all four tasks what role benevolence played in them trusting a robot. $67 \%$ of the participants stated that benevolence would impact their trust in a robot care provider. For example, a participant responded "that would play a lot of role. I would really trust him. If he's doing exactly what I want him to do."

Benevolence only emerged without specifically inquiring about it within the task of bathing which suggests that when a task is personal and vulnerable, the need to feel cared for 


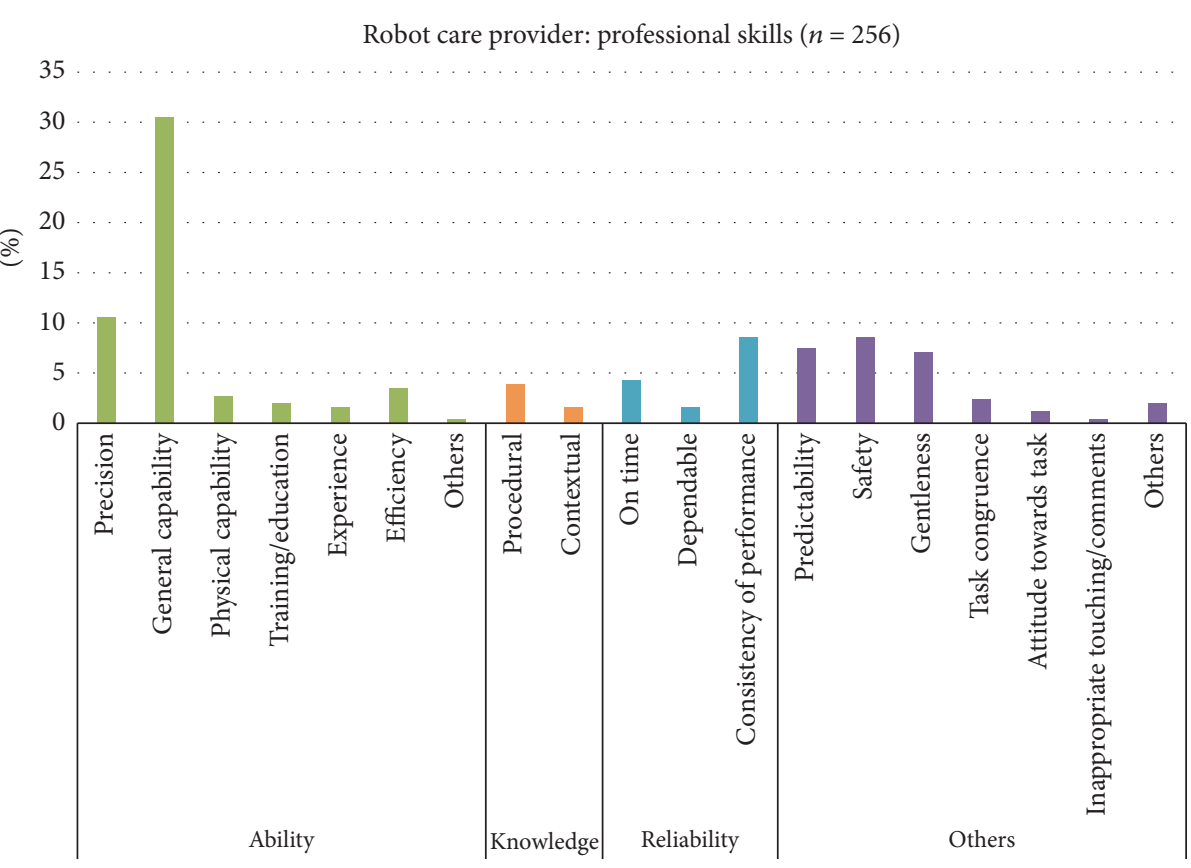

FIgURE 3: Professional skills.
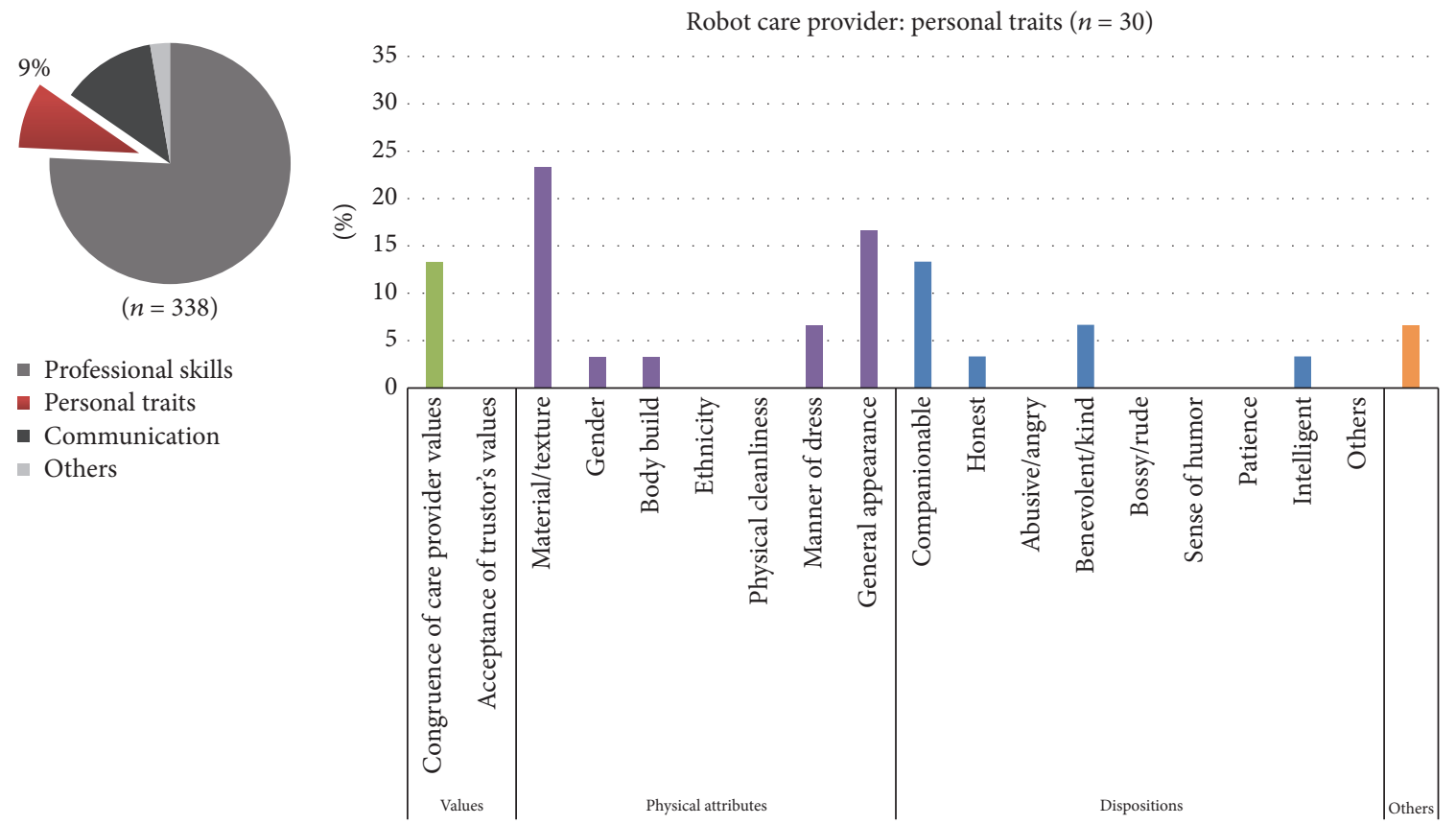

FIgUre 4: Personal traits.

is salient to the older adults. The only other personal trait that seemed to be impacted by task was the concern for the material and texture of the robot which was mentioned only in the tasks that involved human-robot touch like bathing and transferring. This highlights the need for comfort in tasks that involve physical interaction with the robot.

Themes related to personal traits go beyond just general appearance that was identified in human-robot literature before and demonstrate that several themes from humanhuman trust are also relevant to this context, such as the congruence of values and benevolence of the robot. There were also context-specific themes that emerged such as the material and texture of the robot that are a key element in human-robot tasks that involve touch. Older adults also wanted the robot to be companionable and to get along with them as well as their friends and family. All of these demonstrate that they want the robot to go beyond just performing tasks but also to provide them with a feeling of being cared for as well as something that they feel comfortable having others interact with. 
TABLE 5: Professional skills: definitions and examples of factors.

\begin{tabular}{|c|c|c|}
\hline Factor & Definition & Example quote \\
\hline General capability & $\begin{array}{l}\text { Is the robot able to perform that specific } \\
\text { task }\end{array}$ & $\begin{array}{l}\text { "That it got the right bottles. Just if they're gonna just bring } \\
\text { me the bottles, as long as they bring the right bottles, that's } \\
\text { all I would require" }\end{array}$ \\
\hline Precision & $\begin{array}{l}\text { Is the robot exact and accurate in their } \\
\text { performance of the task; does it complete } \\
\text { the task thoroughly }\end{array}$ & $\begin{array}{l}\text { "That (precision) is important to me...because I would want } \\
\text { to feel that it is done right and I wouldn't be able to trust the } \\
\text { robot if it's not done right" }\end{array}$ \\
\hline Consistency of performance & $\begin{array}{l}\text { Is the robot consistent in their task } \\
\text { performance }\end{array}$ & $\begin{array}{l}\text { "Well, some days a human would do it thoroughly and other } \\
\text { days they wouldn't, so the robot would need to do it the } \\
\text { same way every time" }\end{array}$ \\
\hline Safety & $\begin{array}{l}\text { The task is performed with little to no } \\
\text { potential to harm the older adult }\end{array}$ & $\begin{array}{l}\text { "if he dropped me or even if he hurt me while he was doing } \\
\text { it. Now...I don't (know) if I would trust a robot" }\end{array}$ \\
\hline Predictability & $\begin{array}{l}\text { The robot acts in a way that is consistent } \\
\text { with the older adults' expectations }\end{array}$ & $\begin{array}{l}\text { "Yeah that (predictability) is really important. Much more } \\
\text { important than that because you don't interact with a robot } \\
\text { in the same way you do with a person, I don't think" }\end{array}$ \\
\hline Gentleness & $\begin{array}{l}\text { The task is performed with little to no } \\
\text { potential to harm the older adult }\end{array}$ & "That they be gentle, and, because I have a lot of pain" \\
\hline
\end{tabular}

TABLE 6: Personal traits: definitions and examples of factors.

\begin{tabular}{|c|c|c|}
\hline Factor & Definition & Example quote \\
\hline Material/texture & $\begin{array}{l}\text { Is there a preference for the material or texture } \\
\text { or temperature of the robot that would } \\
\text { influence trust }\end{array}$ & $\begin{array}{l}\text { "Have warm hands. Definitely. I can only picture this metal } \\
\text { concoction in my mind. I just can't conceive me going through that" }\end{array}$ \\
\hline General appearance & $\begin{array}{l}\text { Is there any preference for the appearance of } \\
\text { the care provider that would influence trust }\end{array}$ & $\begin{array}{l}\text { "You wouldn't want anything, just like you wouldn't want anything } \\
\text { in your house ugly looking, you'd want something maybe } \\
\text { streamlined. Like a car, whatever, like a wheelchair sometime(s) they } \\
\text { make them-or cane people, they have colored ones. You'd want } \\
\text { something that has a nice appearance to it" }\end{array}$ \\
\hline Companionable & $\begin{array}{l}\text { Is the care provider friendly and sociable and } \\
\text { likes people }\end{array}$ & $\begin{array}{l}\text { "That it would be friendly and be, I don't know how much } \\
\text { personality they have... whatever is programed into him I guess. But } \\
\text {... I would want him to get along with baby dog if it will" }\end{array}$ \\
\hline $\begin{array}{l}\text { Congruence of care } \\
\text { provider values }\end{array}$ & $\begin{array}{l}\text { Do they have the same set of values as the older } \\
\text { adult }\end{array}$ & $\begin{array}{l}\text { "I feel like that for me to trust him, he has to have good values like I } \\
\text { do" }\end{array}$ \\
\hline Benevolence/kind & $\begin{array}{l}\text { Are they a caring person/are they doing the } \\
\text { task because they care about the older adult }\end{array}$ & $\begin{array}{l}\text { ", I feel like that for me to trust him, he has to... really show me that } \\
\text { he wants to help me" }\end{array}$ \\
\hline Manner of dress & $\begin{array}{l}\text { Is the care provider dressed in a way suitable to } \\
\text { the older adult; what they are actually wearing }\end{array}$ & $\begin{array}{l}\text { "If it's for me only, being dressed as a female in some variety... even } \\
\text { if it is some pant suit" }\end{array}$ \\
\hline
\end{tabular}

3.3.3. Communication. Communication has been previously identified as generally impacting trust, but not specifically how communication might be used to support trust. Within the interviews, three main communication themes emerged that older adults perceived as supporting trust: task specific communication, engaging and responsiveness in communication, and the robot able to both understand and communicate clearly with the older adult. See Figure 5 and Table 7 for more details.

These findings not only confirm that communication impacts trust, but it also deepens our knowledge of how it can impact trust by identifying exactly what type and manner of communication older adults perceive as supporting trust. For care tasks, it is not only important that the communication be used to prepare the older adult for what the robot is doing, but that the robot also demonstrates competency in being able to understand and produce appropriate responses. In addition, being able to understand the robot is key for older adults to have successful communication with the robot care provider.

3.3.4. Others. There were some other categories that did not fit into any of the major themes. However, these emerged primarily within the task of bathing. $20 \%$ of participants reported for bathing that they would need experience with the robot before they could trust it. In addition, seven participants explicitly stated that they would not trust the robot with bathing, but this was not mentioned frequently for all the tasks. There was one participant who stated for every task that they would not trust a robot.

\section{Conclusion}

Specialized interventions for specific groups of older adults are needed as this population continues to increase across 
TABLE 7: Communication: definitions and examples of factors.

\begin{tabular}{|c|c|c|}
\hline Factor & Definition & Example quote \\
\hline Task specific & $\begin{array}{l}\text { They explain what they are doing or about to } \\
\text { do related to the task }\end{array}$ & $\begin{array}{l}\text { "Assuring me...that it could do the task that I have } \\
\text { asked it to do, that it has done it before, give me a list } \\
\text { of the places it has been used and how it turned out" }\end{array}$ \\
\hline Responsiveness/engagement & $\begin{array}{l}\text { Answers questions; listens to what they are } \\
\text { saying and responds appropriately }\end{array}$ & "Answering questions and feedback as to how I feel" \\
\hline $\begin{array}{l}\text { Communicates/understands } \\
\text { clearly }\end{array}$ & $\begin{array}{l}\text { Can the older adult understand them and } \\
\text { does the robot understand the older adult }\end{array}$ & $\begin{array}{l}\text { "It would have to demonstrate that it understands its } \\
\text { orders real well. Understands the orders and can recite } \\
\text { them back to me or to someone who is with me" }\end{array}$ \\
\hline
\end{tabular}

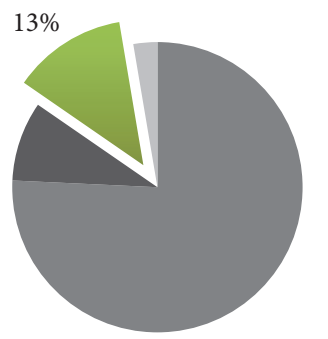

$(n=338)$

- Professional skills

- Personal traits

- Communication

Others

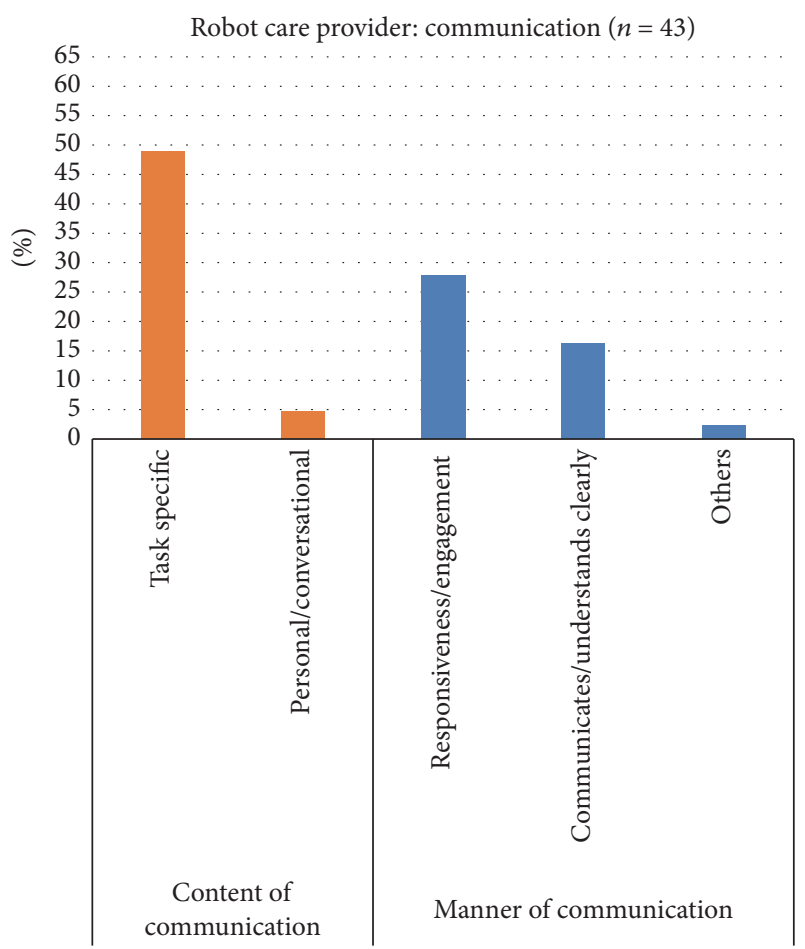

Figure 5: Communication. the world. Robot care providers will be key in helping supply care for older adults and mitigating potential issues caused by decrease of human care providers. As trust is a key element in creating a successful relationship between an older adult and a robot care provider, this study explored what factors older adults perceived as supporting trust within home-care tasks.

The results from this study show that many previously identified themes from both human-human trust literature and human-robot literature emerge within this context. Themes from prior human-robot literature that were confirmed as supporting trust in this context were the capability to perform the task, precision, general appearance, reliability, predictability, and safety of the robot. Human-human themes were the knowledge, values, and benevolence of the robot.

There were also unique themes that emerged in this study including the material/texture, the gentleness, and the companionability of the robot care provider. We found support that communication is key to supporting trust. In addition, this study expands what we have previously understood about the role communication plays in supporting trust by identifying what components of communication can support trust such as the content of the communication being task specific, the responsiveness and engagement of the robot, and the ability of the robot to communicate and understand clearly

To provide better care and improve the lives of older adults, robot care providers should be designed to exemplify these factors and support trust. Although training can be used to mitigate some of these expectations, if the older adults do not perceive the robot as trustworthy then they will not accept or use the robot. We provide design recommendations in Table 8 based on our findings that might enhance the likelihood that older adults will trust a robot care provider.

For the professional skills of the robot, this study highlights that when designing robot as care providers, the robot's ability must go beyond the actual capability to perform the task. Robots caring for older adults must be able to adapt to the older adult's health conditions and specific sensitivities. 
TABLE 8: Design recommendations for robot care providers.

Factors

Professional skills

Personal traits
Design recommendation

(i) Robots should be able to complete the task precisely, reliably, and in a way that the older adult expects

(ii) As many of the older adults receiving care are suffering from various health conditions, it is important to that robots are able to be specialized for individuals for tasks such as transferring and bathing where certain areas might be more sensitive (iii) Design should ensure that appropriate pressure is applied for safety but still be gentle as to not incur harm on the older adult

(i) Need to be able to navigate the social environment in the home including family, friends, and pets of the older adult

(ii) Able to demonstrate to older adult that tasks are being done for their well-being as primary motive

(iii) Flexibility to demonstrate a set of values similar to each older adult (e.g., honesty, task values such as personal standards of cleanliness, or method in which task is performed)

(iv) Material and temperature of robot for tasks that involve touch should be designed to be comfortable for older adult (e.g., not metal cold "hands" for bathing)

(i) Provide information while task is being performed to accurately describe the robots planned goals and steps for that task

(ii) Create controls whether verbal or physical that allow the user to have clear input and output decisions so that they know the robot understood them and responds appropriately

Communication

(a) Audio: ensure that frequency is within common hearing range of older adults and volume is adjustable so that if hearing impaired the volume can be altered to ensure clear communication

(b) Visual: make sure that guidelines are followed for older adults by providing high contrast, large print, and simple steps for navigation

For example, if the older adult fell and now has increased sensitivity due to bruising on their legs or hips, the robot must be able to adjust the way it performs the task of bathing or transferring to prevent incurring pain or discomfort to the older adult. If the robot care provider performs the task the same way as before and the older adult experiences discomfort, it may prevent the older adult from trusting the robot in the future.

When designing robot care providers, it is must be remembered that the robot will now be a part of the older adult's home. This requires not only designing for the older adult, but also taking in consideration the social environment such as family or pets. In addition, as robot care providers might be replacing a part of social interaction that the older adult was previously receiving, it is essential to the older adults that they still feel cared for. Designers should consider building in social components to these robot care providers so that older adults can still feel as though the care they are receiving is purely for their benefit. This study also demonstrated that designers should consider having some options for personalization of the robot in both social and capability aspects. For example, if prior to needing care an older adult would always clean the kitchen before cleaning the rest of the house, they might trust a robot care provider more if they could adjust its behavior to mirror what they previously did.

This study also highlights that clear communication between the older adult and the robot care provider is a key aspect of creating a trusting relationship. Designers should ensure that the robot care provider supports the older adult's knowledge of how the robot will perform the task and simple steps for navigation should be provided to access this information [33]. In addition, designer should pay specific attention to visual and auditory declines associated with aging, whether robots are designed to have a physical interface such as a screen or communicate via auditory displays. Recommendations for designing displays for older adults has been provided by prior literature such as ensuring that text is large and has high contrast of text [33]. For auditory communication, designers should consider having the frequency of communication in the typical audible range for older adults as well as the ability to adjust to volume.

This study provides initial insight into the variables that support trust between older adults and robot care providers, but it was not without limitations. Qualitative interviews allowed for obtaining in-depth information about the factors that support trust within this context, but as the older adults did not interact with a real robot or care technology these findings only provide insights about their attitudes, not their actual interaction behavior. We chose to not expose the older adults to specific robots as many of these technologies are either not in existence or still being developed (not commercially accessible) and we did not want to limit our study to a few specific robots. These initial factors should be further validated as these robots are developed. Another issue is that some individuals in this cohort of older adults have 
limited experience with technology. It is unclear how further experience with technology might impact these factors as well, but we do know that older adults with technology experience are more likely to adopt newer technologies [23]. Therefore, future studies should explore how various technology experiences influences individuals' perceptions of new technologies such as robot care providers. This study provided insights about what factors need further exploration in the future and what aspects older adults perceived as contributing to successful care between them and a robot care provider.

This study expanded the theoretical understanding of what factors support trust in the older adult and care provider context by solidifying that themes from other pieces of trust literature are pertinent to this context, but also by identifying factors that emerged specifically within this context such as gentleness. In addition, these findings give insight into how to design a care provider robot in a way that can support the older adult trusting it. By understanding what factors support trust in this context, we can improve not only the older adults' acceptance of the robot but improve the lives of older adults as well by creating successful interactions between the human and robot care providers.

\section{Disclosure}

NIDILRR is a center within the Administration for Community Living (ACL), Department of Health and Human Services (HHS). The contents of this publication do not necessarily represent the policy of NIDILRR, ACL, or HHS, and the reader should not assume endorsement by the Federal Government. Some details of the method-but none of the results-were presented at a workshop [34].

\section{Conflicts of Interest}

The authors declare that there are no conflicts of interest regarding the publication of this paper.

\section{Acknowledgments}

The contents of this publication were developed under a grant from the National Institute on Disability, Independent Living, and Rehabilitation Research (NIDILRR Grant no. 90RE5016-01-00) under the auspices of the Rehabilitation and Engineering Research Center on Technologies to Support Successful Aging with Disability (TechSAge; http://www.techsage.gatech.edu). The authors appreciate the insights of Charlie Kemp and Jamie Gorman on this project. They would also like to thank Emily McDonald and Lyndsie Koon for their help with the qualitative analysis.

\section{References}

[1] World Health Organization., "Research for the reorientation of national health systems," World Health Organization. Technical Report Series, 2015.

[2] R. C. Mayer, J. H. Davis, and F. D. Schoorman, "An integrative model of organizational trust," Academy of Management Review, vol. 20, no. 3, pp. 709-734, 1995.
[3] L. L. Couch and W. H. Jones, "Measuring levels of trust," Journal of Research in Personality, vol. 31, no. 3, pp. 319-336, 1997.

[4] L. Trojan and O. Yonge, "Developing trusting, caring relationships: home care nurses and elderly clients," Journal of Advanced Nursing, vol. 18, no. 12, pp. 1903-1910, 1993.

[5] L. Berg and E. Danielson, "Patients' and nurses' experiences of the caring relationship in hospital: An aware striving for trust," Scandinavian Journal of Caring Sciences, vol. 21, no. 4, pp. 500506, 2007.

[6] R. Parasuraman and V. Riley, "Humans and automation: use, misuse, disuse, abuse," Human Factors: The Journal of the Human Factors and Ergonomics Society, vol. 39, no. 2, pp. 230253, 1997.

[7] Y. Seong and A. M. Bisantz, "The impact of cognitive feedback on judgment performance and trust with decision aids," International Journal of Industrial Ergonomics, vol. 38, no. 7-8, pp. 608-625, 2008.

[8] P. Madhavan and D. A. Wiegmann, "Similarities and differences between human-human and human-automation trust: An integrative review," Theoretical Issues in Ergonomics Science, vol. 8, no. 4, pp. 277-301, 2007.

[9] J. D. Lee and N. Moray, "Trust, self-confidence, and operators' adaptation to automation," International Journal of Human Computer Studies, vol. 40, no. 1, pp. 153-184, 1994.

[10] S. M. Merritt and D. R. Ilgen, "Not all trust is created equal: Dispositional and history-based trust in human-automation interactions," Human Factors: The Journal of the Human Factors and Ergonomics Society, vol. 50, no. 2, pp. 194-210, 2008.

[11] T. Sanders, K. E. Oleson, D. R. Billings, J. Y. C. Chen, and P. A. Hancock, "A model of human-robot trust: Theoretical model development," in Proceedings of the 55th Human Factors and Ergonomics Society Annual Meeting, (HFES '11), vol. 55, pp. 1432-1436, USA, September 2011.

[12] P. A. Hancock, D. R. Billings, K. E. Schaefer, J. Y. C. Chen, E. J. De Visser, and R. Parasuraman, "A meta-analysis of factors affecting trust in human-robot interaction," Human Factors: The Journal of the Human Factors and Ergonomics Society, vol. 53, no. 5, pp. 517-527, 2011.

[13] N. Ezer, "Is a robot an appliance, teammate, or friend? Agerelated differences in expectations of and attitudes towards personal home-based robots".

[14] D. R. Billings, K. E. Schaefer, J. Y. C. Chen, and P. A. Hancock, "Human-robot interaction: Developing trust in robots," in Proceedings of the 7th Annual ACM/IEEE International Conference on Human-Robot Interaction, (HRI '12), pp. 109-110, USA, March 2012.

[15] W. A. Rogers and T. L. Mitzner, "Human-robot interaction for older adults," Encyclopedia of Computer Science and Technology, pp. 1-11, 2017.

[16] C.-A. Smarr, T. L. Mitzner, J. M. Beer et al., "Domestic robots for older adults: attitudes, preferences, and potential," International Journal of Social Robotics, vol. 6, no. 2, pp. 229-247, 2014.

[17] J. Beer, A. Prakash, C. Smarr et al., "Older users' acceptance of an assistive robot: Attitudinal changes following brief exposure," Gerontechnology, vol. 16, no. 1, pp. 21-36, 2017.

[18] K. E. Olson, Understanding the construct of human trust in domestic service robots, Georgia Institute of Technology, 2013.

[19] A.-S. Melenhorst, W. A. Rogers, and D. G. Bouwhuis, “" Older adults" motivated choice for technological innovation: evidence for benefit-driven selectivity," Psychology and Aging, vol. 21, no. 1, pp. 190-195, 2006. 
[20] A. C. Costa, "Work team trust and effectiveness," Personnel Review, vol. 32, no. 5, pp. 605-672, 2003.

[21] D. Bernstein, K. Crowley, and I. Nourbakhsh, "Working with a robot: Exploring relationship potential in human-robot systems," Interaction Studies, vol. 8, no. 3, pp. 465-482, 2007.

[22] R. E. Stuck, Understanding Dimensions of Trust between Older Adults and Human or Robot Care Providers, Georgia Institute of Technology, 2017.

[23] S. J. Czaja, N. Charness, A. D. Fisk et al., "Factors predicting the use of technology: findings from the center for research and education on aging and technology enhancement (CREATE)," Psychology and Aging, vol. 21, no. 2, pp. 333-352, 2006.

[24] L. H. Barg-Walkow, T. L. Mitzner, and W. A. Rogers, "Technology Experience Profile".

[25] J. A. Sanford, P. C. Griffiths, P. Richardson, K. Hargraves, T. Butterfield, and H. Hoenig, "The effects of in-home rehabilitation on task self-efficacy in mobility-impaired adults: A randomized clinical trial," Journal of the American Geriatrics Society, vol. 54, no. 11, pp. 1641-1648, 2006.

[26] Z. S. Nasreddine, N. A. Phillips, V. Bédirian et al., "The montreal cognitive assessment, MoCA: a brief screening tool for mild cognitive impairment," Journal of the American Geriatrics Society, vol. 53, no. 4, pp. 695-699, 2005.

[27] D. Wechsler, WAIS-III: Wechsler adult intelligence scale, Psychological Corporation, 1997.

[28] C. T. K. C, R. W. Mitzner T, and C. T. K. C. R. W. Mitzner, "Identifying the potential for robotics to assist older adults in different living environments," International Journal of Social Robotics, vol. 6, no. 2, pp. 213-227, 2014.

[29] H. F. Hsieh and S. E. Shannon, "Three approaches to qualitative content analysis," Qualitative Health Research, vol. 15, no. 9, pp. 1277-1288, 2005.

[30] C. Pope, S. Ziebland, and N. Mays, "Qualitative research in health care Analysing qualitative data," British Medical Journal, vol. 320, no. 7227, pp. 114-116, 2000.

[31] J. Saldana, The Coding Manual for Qualitative Researchers, vol. 36, Sage Publications, England, UK, 2nd edition, 2014.

[32] T. L. Mitzner, R. Stuck, J. Q. Hartley, J. M. Beer, and W. A. Rogers, "Acceptance of televideo technology by adults aging with a mobility impairment for health and wellness interventions," Journal of Rehabilitation and Assistive Technologies Engineering, vol. 4, 2017.

[33] A. D. Fisk, W. A. Rogers, N. Charness, S. J. Czaja, and J. Sharit, Designing for older adults: Principles and creative human factors approaches, 2009.

[34] R. E. Stuck and W. A. Rogers, "Understanding older adult's perceptions of factors that support trust in human and robot care providers," in Proceedings of the 10th International Conference on PErvasive Technologies Related to Assistive Environments (PETRA '17), pp. 372-377, Greece, June 2017. 


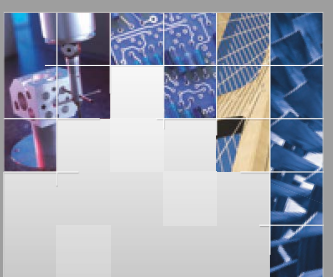

\section{Enfincering}
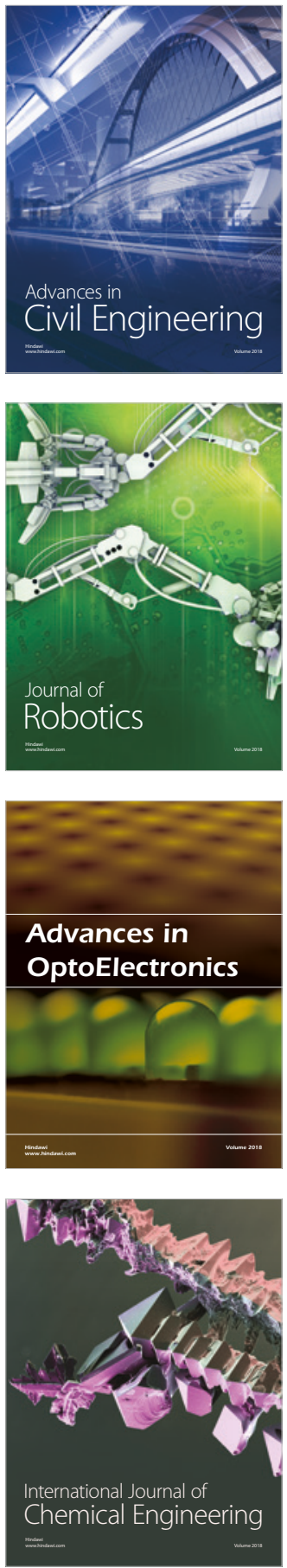

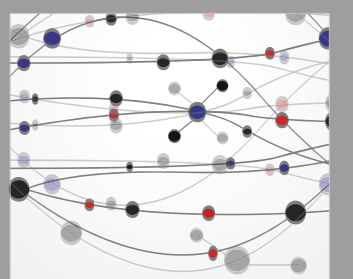

\section{Rotating \\ Machinery}

The Scientific World Journal

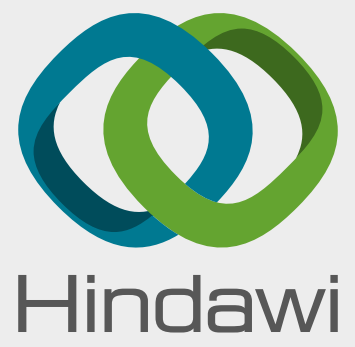

Submit your manuscripts at

www.hindawi.com
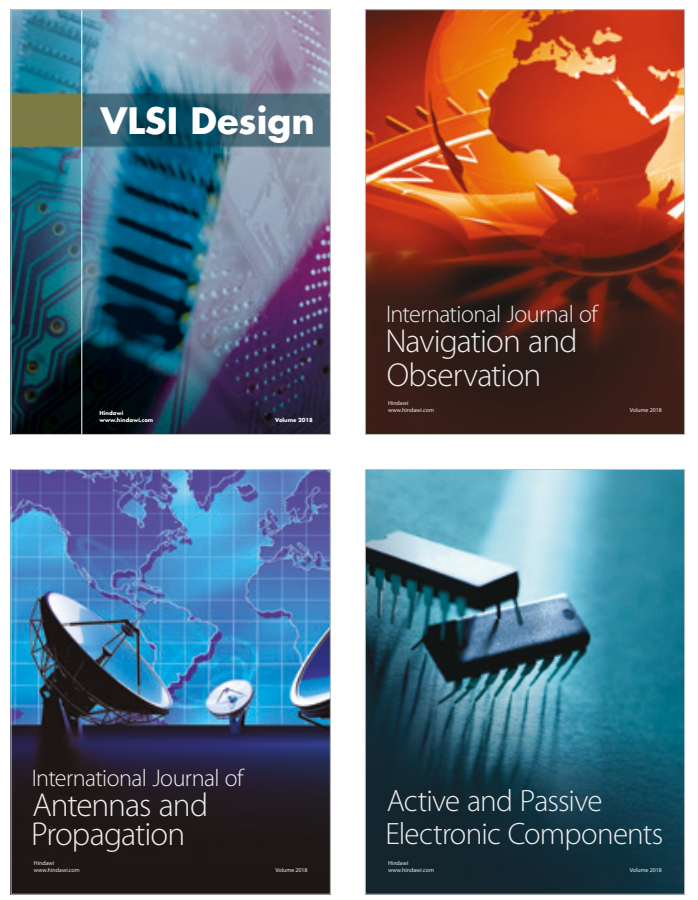
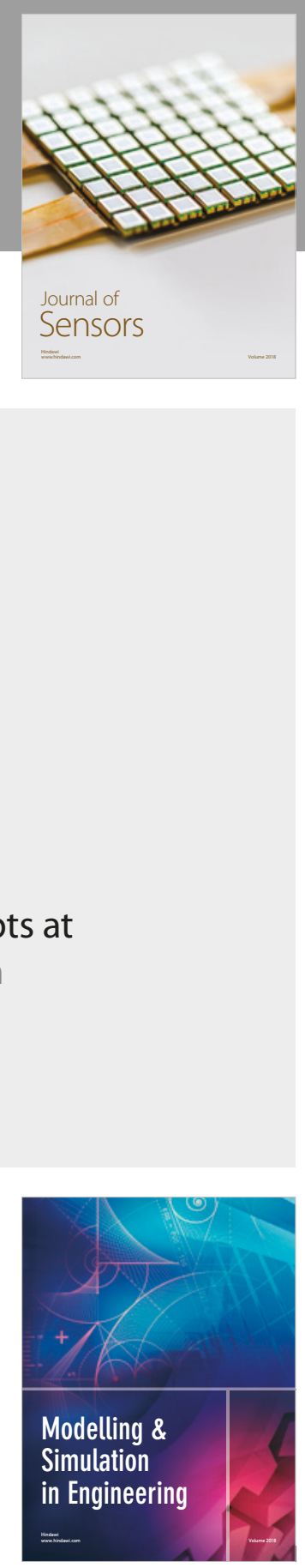

\section{Advances \\ Multimedia}
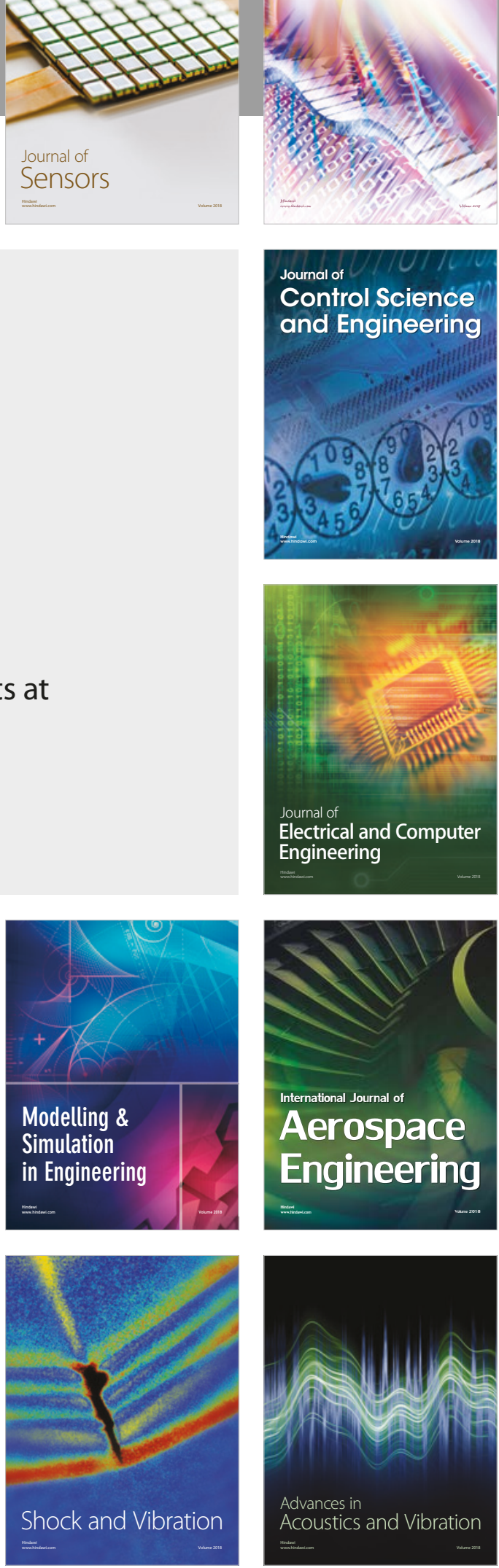